\title{
Comparative Determination of Phosphorus Fractions in Coastal Surface Sediment (NE Mediterranean Sea) by ICP-OES and UV/VIS Spectrometry
}

\author{
Isil Aydin ${ }^{a}$, Zihni Temel ${ }^{\mathrm{b}}$, Beniz Gunduz ${ }^{\mathrm{c}}$, and Firat Aydin ${ }^{\mathrm{d}, *}$ \\ a Dicle University, Pharmacy Faculty, Analytical Chem. Depart., Diyarbakır, Turkey \\ ${ }^{b}$ Dicle University, Architecture Faculty, Diyarbakir, Turkey \\ c Selcuk University, Science Faculty, Chemistry Department, Konya, Turkey \\ d Dicle University, Science Faculty, Chemistry Department, Diyarbakir, Turkey
}

\section{INTRODUCTION}

Surface sediments play an important role in the overall nutrient dynamics of water science. It has been identified as one of the leading nonpoint source of pollutants (1). Phosphorus (P) availability is regarded as the most important factor for determining the water quality of a sea. However, not all of the P fractions can be released from the sediment. Thus, to assess the risk of eutrophication in the sea, it is necessary to know not only the total P content in the surface sediments, but also the concentrations of the different $P$ fractions (2-4). Chemical sequential extractions have been used widely to describe the many different fractions in which $\mathrm{P}$ occurs in the sediments. The sorption of phosphate on sediments plays an important role on transport, degradation, and the ultimate fate of $\mathrm{P}$ in the marine ecosystems $(5,6)$.

The fractionation of total $\mathrm{P}$ in different forms is necessary to understand the phosphate exchange mechanisms in sediments, its potential removal from the water column, and the availability of $\mathrm{P}$ for primary producers $(7,8)$. All sorption/desorption studies performed in the literature related to inorganic $P$ species have been conducted exclusively using phosphate $(9$, 10). Phosphorus undergoes transitions in the sea environment and the final product is orthophosphates (2). Thus, it is likely that

\footnotetext{
*Corresponding autbor.

:E-mai: firataydin01@gmail.com Tel: ????
}

\begin{abstract}
The role of phosphorus $(\mathrm{P})$ in sediments in promoting marine eutrophication can be more efficiently evaluated by considering different $\mathrm{P}$ fractions instead of total $\mathrm{P}$ content. This paper presents the $\mathrm{P}$ distribution (total $\mathrm{P}$, organic $\mathrm{P}$, and fractions of inorganic $\mathrm{P}$; loosely adsorbed $\mathrm{P}$, and $\mathrm{P}$ bound to aluminium, $\mathrm{P}$ bound to calcium, and $\mathrm{P}$ bound to iron, as well as total inorganic P) in surface sediments collected in June 2015 at the NE Mediterranean Sea (due to extensive tourism is under anthropogenic pressure) using chemical (sequential extraction) fractionation techniques. A number of fractions were collected for each reagent for subsequent colorimetric determination using UV/Vis spectrometry and ICPOES determination. The two methods show similar results for the $\mathrm{P}$ and the concentrations are in good agreement with the reference values. The results presented P-bound calcium as the major $\mathrm{P}$ fraction in the surface sediments collected, mainly due to the oversaturation of calcite and the coprecipitation of phosphate. Relative abundances of the remaining $\mathrm{P}$ fractions follow the order: Fe-P > Al-P > loosely bound $\mathrm{P}$ for coastal surface sediment.
\end{abstract}

organisms with the ability to utilize alternative sources of $P$, namely reduced $\mathrm{P}$, may be at an ecological advantage under the limiting conditions. Extensive input of $\mathrm{P}$ due to over-fertilization, and industrial and domestic wastewater pollution results in its over-abundance in the aquatic media (11). Consequently, it is clear that monitoring of the $\mathrm{P}$ content in surface sediments is essential to the quality and avoidance of eutrophication of the aquatic environment (12-14).

In recent years, an exponential increase in aquaculture production in the Mediterranean Sea has caused various antrophogenic environmental problems. (15). Various pollutants may be adsorbed in the sediments accumulated at the bottom of the Mediterranean Sea which may accumulate over long periods of time and can act as new pollutant sources to the overlying water. The Eastern Mediterranean Sea is the largest body of water in the world which, at present, is phosphate limited. This unusual nutrient limitation may be due to the adsorption of phosphate by inorganic particulate matter in the deep water column and its subsequent removal into the sediments (16). The importance of sediments depends on the chemical form of $P$ in which this element is combined. For this reason, the study of $\mathrm{P}$ speciation is particularly interesting. Phosphorus can be transferred from water to sediment through biochemical and physical reactions, such as ion exchange, adsorption, and precipitation, and also could be released from the bottom sediments as the overlying water quality changes. Most of the $\mathrm{P}$ incorporates into different sedimentary P-fractions and transports into the sediments in these particulate forms by sedimentation-deposition and sorption-precipitation $(17,18)$. 
The aim of the present study was to investigate the amount and forms of $\mathrm{P}$ in the coastal sediments of the NE Mediterranean Sea at Side, Antalya, Turkey, using a sequential extraction procedure. The two analytical methods of UV-Vis and ICP-OES were applied to determine the $\mathrm{P}$ forms.

\section{EXPERIMENTAL}

\section{Sampling}

Coastal surface sediment samples were collected daily near Side from a vessel (Lat. $36.76 \mathrm{~N}$ vs. Long. $31.38 \mathrm{E}$ ) on the Mediterranean coast of Turkey during June 2015. The depth at the study site ranged from 0.5 to $1.5 \mathrm{~m}$. The top $5 \mathrm{~cm}$ of the coastal surface sediment samples were collected with a stainless steel grab sampler, placed into $1 \% \mathrm{HNO}_{3}$ acid-washed nylon bags to prevent contamination, closed tightly, refrigerated at $4{ }^{\circ} \mathrm{C}$ until transport to the laboratory where they were stored at $-20{ }^{\circ} \mathrm{C}$ until further treatment.

\section{Reagents and Standard Solutions}

Suprapur ${ }^{\circledR}$ grade reagents were used when available (Merck, Darmstadt, Germany) or analytical grade, and used without further purification. A stock standard solution of orthophosphate $\left(100 \mathrm{mg} \mathrm{L}^{-1} \mathrm{P}\right)$ was prepared from $\mathrm{KH}_{2} \mathrm{PO}_{4}$ (Merck). Working solutions were prepared daily by stepwise dilution of the stock P solution. Amounts of $1.0 \mathrm{M}$ of $\mathrm{NH}_{4} \mathrm{Cl}, 0.5 \mathrm{M}$ of $\mathrm{NH}_{4} \mathrm{~F}, 0.1 \mathrm{M}$ of $\mathrm{NaOH}$, and $1.0 \mathrm{M}$ of $\mathrm{H}_{2} \mathrm{SO}_{4}$ were prepared and used as the extractants. In all dilution and standard preparations, Milli- ${ }^{\circledR}$ deionized water (Millipore Corporation, Bedford, MA, USA) was used. All glass apparatus used throughout this study were kept in Pyrex ${ }^{\circledR}$ containers, permanently kept full with $1.0 \mathrm{M} \mathrm{HNO}_{3}$ when not in use.

Certified reference material (CRM) NCS DC73316 Chinese
Stream Sediment (LGC Standards) was used to assess the analytical and instrumental accuracy of the methods (Table I).

Method A: Approximately $5 \mathrm{~g}$ of coastal surface sediment samples was dissolved in a $10-\mathrm{mL}$ mixture of perchloric acid (70\%), sulfuric acid (98\%), and HF (48\%) (1:1:1). Following filtration, total $\mathrm{P}$ was determined by ICP-OES and UV-VIS as comparison (Table II). A quantitative method was described for the speciation of $\mathrm{P}$ in surface sediments (19). The same procedure of method $\mathrm{A}$ was applied to the standard reference material .

Determination of total inorganic $P$ was carried out using the method shown in (Table III). Satisfactory reproducibility for total $\mathrm{P}$ in sediments was obtained in replicate samples (n:30). The contents of different $\mathrm{P}$ fractions were determined using the sequential extraction procedure in surface sediment
(Table IV). The extracts were centrifuged and the supernatants filtered through a $0.45-\mu \mathrm{m}$ GF/C filter membrane (Sartorius AG, Goettingen, Germany) and the soluble $\mathrm{P}$ in each sample was determined. This extraction procedure divided the inorganic $\mathrm{P}$ fractions in the sediment into loosely sorbed $\mathrm{P}\left(\mathrm{NH}_{4} \mathrm{Cl}-\mathrm{P}\right)$, $\mathrm{P}$ bound to aluminium $\left(\mathrm{NH}_{4} \mathrm{~F}-\mathrm{P}\right)$, $\mathrm{P}$ bound to iron (NaOH-P), and $\mathrm{P}$ bound to calcium $\left(\mathrm{H}_{2} \mathrm{SO}_{4} \mathrm{P}\right)$. The reliability and comparability of data for any of these fractions will depend on the operational protocols used and the accuracy of the method (20-21).

\section{Methods Used for the Determi- nation of $P$ Forms}

Two analytical procedures were applied to determine the $\mathrm{P}$ forms:

(a) P species analyses were performed with an Optima ${ }^{\mathrm{TM}} 2100 \mathrm{DV}$ inductively coupled plasma optical emission spectrometer (ICP-OES),

TABLE I

Accuracy Assessment Through the Analysis of CRM NCS DC 73316 Chinese Stream Sediment ( $\mu \mathrm{g} \mathrm{g}^{-1}$, Dry Weight, DW)

\begin{tabular}{ccccc}
\hline Element & Instrument & $\begin{array}{c}\text { Certified Value } \\
\left(\mu \mathrm{g} \mathrm{g}^{-1}\right)\end{array}$ & $\begin{array}{c}\text { Found Value } \\
\left(\mu \mathrm{g} \mathrm{g}^{-1}\right)\end{array}$ & $\begin{array}{c}\text { Recovery } \\
(\%)\end{array}$ \\
\hline $\mathrm{P}$ & UV/VIS & $1020 \pm 42$ & $1016 \pm 8$ & 99.61 \\
$\mathrm{P}$ & ICP-OES & $1020 \pm 42$ & $1017 \pm 5$ & 99.70 \\
\hline
\end{tabular}

TABLE II

Method for Total Phosphorus Determination in Coastal Surface Sediments

\begin{tabular}{cccl}
\hline Step & Nominal Fraction & Extractant & Extraction Conditions \\
\hline 1. & Total Phosphorus & $\begin{array}{c}\mathrm{H}_{2} \mathrm{SO}_{4}, \mathrm{HClO}_{4} \\
\text { and } \mathrm{HF}\end{array}$ & $\begin{array}{l}\text { Boiling, 1 h, Shaking, } \\
\text { Centrifuging 5000 rpm }\end{array}$ \\
\hline
\end{tabular}

TABLE III

Method for Total Inorganic Phosphorus Determination in Coastal Surface Sediments

\begin{tabular}{cccl}
\hline Step & Nominal Fraction & Extractant & Extraction Conditions \\
\hline Acid Extract & Inorganic $\mathrm{P}$ & $\mathrm{H}_{2} \mathrm{SO}_{4}$ and $\mathrm{NH}_{4} \mathrm{~F}$ & $\begin{array}{l}\text { Shaking } 2 \mathrm{~h}, 25^{\circ} \mathrm{C}, \\
\text { Centrifuging } 5000 \mathrm{rpm}\end{array}$ \\
Base Extract & Organic $\mathrm{P}$ & $3 \mathrm{M} \mathrm{NaOH}$ & $\begin{array}{l}\text { Shaking } 12 \mathrm{~h}, 25^{\circ} \mathrm{C}, \\
\text { Centrifuging } 5000 \mathrm{rpm}\end{array}$ \\
& & &
\end{tabular}


and its operating conditions are listed in Table V (PerkinElmer, Inc., Shelton, CT, USA). Selection of the instrumental parameters and optical wavelength were based on obtaining good sensitivity, reasonable detection limits, and eliminating interferences. The limits of detection (LOD) and limits of quantification (LOQ) for each metal were determined by performing 10 independent analyses of a blank solution spiked with the metal at a level of lower concentration of the analytical curve. The LOD and LOQ were calculated from the standard deviation $(\sigma)$ of these determinations $(\mathrm{LOD}=3 \times \sigma$ and $\mathrm{LOQ}=$ $10 \times \sigma)$. With ICP-OES, the LOD obtained was $0,034 \mathrm{mg} \mathrm{kg}^{-1}$ and the LOQ $0.113 \mathrm{mg} \mathrm{kg}^{-1}$. Spectral wavelength selection for P determination by ICP-OES is very important to achieve minimum interference and maximum detection and $213.617 \mathrm{~nm}$ was chosen for the $P$ analyses (3, 22, 23).

(b) A PerkinElmer ${ }^{\circledR}$ Lambda 35 UV/VIS (PerkinElmer, Inc., Shelton, CT, USA) was used to determine the $P$ species at $860 \mathrm{~nm}$. The molybdenum blue method (10) was developed and used for the determination of phosphate which is the most abundant form of $\mathrm{P}$ in the environment. In addition, determination of other phosphorus species is commonly performed by their conversion into phosphate and their colorometric analysis by UV spectrophotometry. The reliability and comparability of data for any of these fractions will depend on the operational protocols used and the accuracy of the method. Most manual and automated methods used for $\mathrm{P}$ determination are based on the reaction of phosphate with an acidified molybdate reagent to yield phosphomolybdate heteropolyacid, which is then reduced to an intensely colored blue compound and determined spectrophotometrically (15).

\section{RESULTS AND DISCUSSION}

In this study, fractionation of the $P$ compounds was carried out as well as total $\mathrm{P}$ determination in coastal surface sediments (mainly sands) from the NE Mediterranean Sea. The $P$ released from the sediments originates mainly from the inorganic P fractions. Hence, the determination of the inorganic $\mathrm{P}$ form was the focus rather than the other $\mathrm{P}$ forms. The concentrations of different $P$ fractions in the coastal surface sediments were determined by UV/VIS spectrophotometry and ICP-OES for comparison (Table VI and Table VII ) (24).

\section{A $_{\text {Somic }}^{\text {tomectroscopy }}$}

Certified reference material NCS DC 73316 Chinese Stream Sediment was analyzed to check for accuracy and the results were found to be in good agreement with the certified value (Table I). Total $\mathrm{P}$ was determined as well as the $\mathrm{P}$ fractions. It was established that the sediments contain more inorganic $\mathrm{P}$ than organic P. Organic $P$ was calculated by subtracting the total inorganic $P$ from total $P$. The organic P values were $12.19 \pm 1.27$ $\mathrm{mg} \mathrm{kg}^{-1}$ for ICP-OES and $10.09 \pm 0.75$ $\mathrm{mg} \mathrm{kg}^{-1}$ for UV-VIS. The inorganic $\mathrm{P}$ values were $324.86 \pm 2.91 \mathrm{mg} \mathrm{kg}^{-1}$ for ICP-OES and $325.02 \pm 1.91 \mathrm{mg}$ $\mathrm{kg}^{-1}$ for UV-VIS. Inorganic $\mathrm{P}$ was

\section{TABLE IV}

Method for Inorganic Phosphorus Forms Determination in Costal Surface Sediments

\begin{tabular}{|c|c|c|c|}
\hline Step & Nominal Fraction & Extractant & Extraction Conditions \\
\hline I & Loosely bound P & $1 \mathrm{M} \mathrm{NH} 4 \mathrm{Cl}$ & $\begin{array}{l}\text { Shaking } 1 \mathrm{~h}, 25^{\circ} \mathrm{C} \text {, } \\
\text { Centrifuging } 5000 \mathrm{rpm}\end{array}$ \\
\hline II & $\mathrm{P}$ bound to $\mathrm{Al}$ & $0.5 \mathrm{M} \mathrm{NH}_{4} \mathrm{~F}$ & $\begin{array}{l}\text { Shaking } 1 \mathrm{~h}, 25^{\circ} \mathrm{C} \text {, } \\
\text { Centrifuging } 5000 \mathrm{rpm}\end{array}$ \\
\hline III & $\mathrm{P}$ bound to $\mathrm{Fe}$ & $0.1 \mathrm{M} \mathrm{NaOH}$ & $\begin{array}{l}\text { Shaking } 24 \mathrm{~h}, 25^{\circ} \mathrm{C} \text {, } \\
\text { Centrifuging } 5000 \mathrm{rpm}\end{array}$ \\
\hline IV & $\mathrm{P}$ bound to $\mathrm{Ca}$ & $1 \mathrm{M} \mathrm{H}_{2} \mathrm{SO}_{4}$ & $\begin{array}{l}\text { Shaking } 3 \mathrm{~h}, 25^{\circ} \mathrm{C} \text {, } \\
\text { Centrifuging } 5000 \mathrm{rpm}\end{array}$ \\
\hline
\end{tabular}

TABLE V

Operating Conditions of the Optima 2100 DV ICP-OES

\begin{tabular}{ll}
\hline Parameters & \\
\hline RF power & $1450 \mathrm{~W}$ \\
Plasma gas flow rate & $15 \mathrm{~L} \mathrm{~min}^{-1}$ \\
Auxiliary gas flow rate & $0.2 \mathrm{~L} \mathrm{~min}^{-1}$ \\
Nebulizer gas flow rate & $0.8 \mathrm{~L} \mathrm{~min}^{-1}$ \\
Sample flow rate & $1.5 \mathrm{~L} \mathrm{~min}{ }^{-1}$ \\
View mode & Axial \\
Read & Peak area \\
Source equilibration time & $15 \mathrm{~s}$ \\
Read delay & $50 \mathrm{~s}$ \\
Replicates & 3 \\
Spray chamber & Scott type spray chamber \\
Nebulizer & Cross-Flow GemTip ${ }^{\circledR}$ Nebulizer \\
& (HF resistant) \\
Detector & CCD \\
Analytical wavelength & P: 213.617 nm \\
\hline
\end{tabular}


found to be higher than organic $\mathrm{P}$ for the studied areas (Table VI). This is one of the most important features differentiating sediments from soils where organic forms predominate.

\section{Speciation of Inorganic $P$}

It is now widely accepted that the accessibility of the various elements for biota uptake depends strongly on their specific chemical forms and binding sites. A commonly used technique for identification of the phase associations of elements in solid phases is based on the application of sequential extraction. In this study, speciation of inorganic $\mathrm{P}$ was carried out using sequential extractions of the sediment, each releasing four forms of inorganic $\mathrm{P}$ as follows: loosely sorbed $\mathrm{P}$, $\mathrm{P}$ bound to aluminium (P-Al), $\mathrm{P}$ bound to iron (P-Fe), and $\mathrm{P}$ bound to calcium ( $\mathrm{P}-\mathrm{Ca})$. The $\mathrm{P}$ released from the surface sediments originates from the inorganic $P$ fractions. Hence, the $\mathrm{P}$ fractions were focused on the inorganic P fraction (Table VII). $\mathrm{P}$ undergoes transitions in the environment with the final product being orthophosphates. Apatite group minerals are by far the most prevailing phosphate minerals in rocks, soils, and sediments (10).

The results show that calciumbound $\mathrm{P}$ is the major $\mathrm{P}$ form in the study area, related mainly to the oversaturation of calcite and coprecipitation of phosphate. The co-precipitation kinetics of $\mathrm{P}$ and calcite may be described in terms of simultaneous precipitation of calcite and adsorption of inorganic $\mathrm{P}$ onto its surface sediment (Table VII).

The typical summer climate of the Eastern Mediterranean is hot and humid, in the winter mild and rainy, with short transitional seasons. Phosphate is known to be the limiting nutrient for phytoplankton production in the Mediterranean and as a result, the Eastern Mediter- ranean surface and deep waters are characterized with a high $\mathrm{N}: \mathrm{P}$ ratio (>20:1). Since tourism and agriculture are the main activities in that region, an increase in the total $P$ content at the sediment level is related to a progressive eutrophication. It can be stated that the chemical co-precipitation of phosphate and the biological and hydrological processes control the P concentration in the surface sediments rather than external factors such as the lithology of drainage and sewage (25).

The found values obtained of total $\mathrm{P}$ were $1016 \pm 8 \mu \mathrm{g} \mathrm{g}^{-1} \mathrm{fpr}$ UV/VIS and $1017 \pm 5 \mu \mathrm{g} \mathrm{g}^{-1}$ using ICP-OES, while the certified value was $1020 \pm 42 \mu \mathrm{g} \mathrm{g}^{-1}$ (Table I).

The accessibility of the elements for biota uptake strongly depends on their specific chemical forms and binding sites. A commonly used technique for identification of the phase associations of elements in solid phases is based on the application of sequential extractions. The chemical fractionation technique, such as sequential extraction, was applied, and the results are listed in Table IV. The total inorganic $P$ in the coastal surface sediments were found to con- sist only of the four forms of inorganic $\mathrm{P}$ examined in this work. No other forms of inorganic $\mathrm{P}$ were investigated in the coastal surface sediments and organic $P$ was present in negligible amounts.

The $\mathrm{P}$ released into the coastal surface sediments at Side mainly originated from the inorganic $P$ fraction (Table VI). The results presented $\mathrm{P}$ bound calcium as the major $\mathrm{P}$ fraction in surface sediments related mainly to the oversaturation of calcite and co-precipitation of phosphate. Relative abundances of the remaining $\mathrm{P}$ fractions follow the order: Fe-P > Al-P > loosely bound $\mathrm{P}$ (Table VII). The solubility of the $\mathrm{Ca}, \mathrm{Fe}(\mathrm{III})$, and $\mathrm{Al}$ phosphates depends strongly on the redox potential and $\mathrm{pH}$ of the environment. Under the reducing conditions, the oxidized form of iron, Fe(III), is converted to the reduced form, $\mathrm{Fe}(\mathrm{II})$. The former Fe(III) fractions are a poorly soluble compound with phosphate ions, while the latter Fe(II) is a soluble compound.

Intensive decomposition processes lead to the inorganic phosphate form of $\mathrm{P}$ which binds metal ions. The most abundant form of inorganic $P$ in the studied coastal surface sediments is

TABLE VI

Average Values Determined Using UV/VIS and ICP-OES of Total and Inorganic P Speciation for Coastal Surface Sediments

\begin{tabular}{lll}
\hline P Fractions & \multicolumn{1}{c}{ ICP-OES } & \multicolumn{1}{c}{ UV/VIS } \\
\hline Total P $\left(\mathrm{mg} \mathrm{kg}^{-1}\right)$ & $337.05 \pm 4.13$ & $335.11 \pm 3.47$ \\
Inorganic $\mathrm{P}\left(\mathrm{mg} \mathrm{kg}^{-1}\right)$ & $324.86 \pm 2.91$ & $325.02 \pm 1.91$ \\
Organic $\mathrm{P}\left(\mathrm{mg} \mathrm{kg}^{-1}\right)$ & $12.19 \pm 1.27$ & $10.09 \pm 0.75$ \\
\hline
\end{tabular}

TABLE VII

Mean Values of Inorganic Phosphorus Speciation

\begin{tabular}{lcc}
\hline P Fraction & ICP-OES $\left(\mathrm{mg} \mathrm{kg}^{-1}\right)$ & UV/VIS $\left(\mathrm{mg} \mathrm{kg}^{-1}\right)$ \\
\hline P-Inorganic & $324.86 \pm 2.91$ & $325.02 \pm 1.36$ \\
P-Ca & $267.33 \pm 2.57$ & $265.16 \pm 1.72$ \\
P-Fe & $31.68 \pm 1.94$ & $31.96 \pm 1.71$ \\
P-Al & $19.93 \pm 0.68$ & $20.47 \pm 0.82$ \\
P- Loosely Bound & $5.80 \pm 0.39$ & $7.41 \pm 0.31$ \\
\hline
\end{tabular}


calcium-bound $\mathrm{P}\left(\mathrm{H}_{2} \mathrm{SO}_{4}\right.$-extracted $\mathrm{P})$. The results show P-bound calcium as the major $P$ form, due mainly to the oversaturation of calcite and co-precipitation of phosphate. The co-precipitation kinetics of $P$ and calcite may be described in terms of simultaneous precipitation of calcite and adsorption of inorganic P onto its surface. A number of fractions were collected for each reagent for subsequent colorimetric determination using a UV/VIS spectrometer and compared with ICPOES analysis. The obtained $\mathrm{P}$ concentrations of all phases were also compared with the certified values and with the values obtained from total digestion. For the $\mathrm{P}$ analysis, it was found that these two methods achieve the same results and the concentrations are in good agreement with the reference values.

\section{CONCLUSION}

This paper presents the results of the determination of inorganic and organic forms of $\mathrm{P}$ in coastal surface sediments from the NE Mediterranean Sea by UV/VIS spectrophotometry and ICP-OES for comparison. Calcium-bound $\mathrm{P}$ was found as the most abundant form of inorganic $P$ in the sediments. Relative abundances of the remaining $P$ forms follow the order: P-Fe $>$ P-Al > loosely bound $\mathrm{P}$. The results are in good agreement with the reference values. The sum of $\mathrm{P}$ concentrations of all phases were compared with the certified values and with the values obtained from total digestion. The differences between the certified and measured results for $P$ were found to be less than $2 \%$ and $1 \%$ using UV/VIS and ICP-OES, respectively.

Received February 14, 2018.

\section{REFERENCES}

1. N.R. Amaizah, D. Cakmak, E. Saljnikov, G. Roglic, V. Mrvic, R. Krgovic, and D. Manojlovic, J. Serb. Chem. Soc. 77, 971 (2012).

2. A. Aviles, J. Rodero, V. Amores, I. Vicente, M.I Rodriguez, and F.X. Niell, J. Hydrol. 331, 396 (2006).

3. I. Aydin, F. Aydin, A. Saydut and C. Hamamci, J. Hazard Mater. 168, 664 (2009).

4. J.Y. Wang and H.K Pant, Chem. Speciation. Bioavail. 22, 171 (2010).

5. P.C. Onianwa, O.U. Oputu, O.E. Oladiran and O.O. Olujimi, Chem. Speciation Bioavail. 25, 24 (2013).

6. Q.M. Li, X.X Wang, R. Bartlett, G. Pinay, G. D. Kan, W. Zhang, and J.X Sun, Water Environ. Res. 84, 2037 (2012).

7. F. Aydin, A. Saydut, I Aydin, C. Hamamci, At. Spectrosc. 32, 194 (2011).

8. M. Jalali, Soil Sediment Contam. 19, 560 (2010).

9. M. Waldeback, E. Rydin and K. Markides, .Intern. J. Environ. Anal. Chem. 72, 257 (2013).

10. I. Aydin, S. Imamoglu , F. Aydin, A. Saydut and C. Hamamci, Microchem. J. 91, 63 (2009).

11. M. Al-Hwaiti, J. Tardio, J.H. Reynolds and S. Bhargava, Soil and Sediment Contam. 23, 417 (2014).

12. R. Indiati and A.N. Sharpley, Commun. Soil Sci. Plant Anal. 29, 2429 (1998).

13. N. Dogan- Saglamtimur and S. Tugrul, Fresenius' Environm. Bull. 13, 1288 (2004).

14. D.S. Bi, X.P. Guo, Z.H. Cai, X.F. Gao, Y. Li, J.L. Guo, X.J. Long, Z.Q. Zhong and Y.R. Liang, Water Sci. Technol..66, 2688 (2012).

15. B. Gunduz, I. Aydin, S. Bakirdere, A. Saydut and F. Aydin At. Spectrosc. 31, 196 (2010).

16. I. Aydin, F. Aydin and C. Hamamci, Water Environ. Res. 82, 2265 (2010).

17. B. Gunduz, F. Aydın, I. Aydın and C. Hamamci, Microchem J. 98, 72 (2011).
18. L. Medici, J. Bellanova, C. Belviso, F. Cavalcante, A. Lettino, P.P. Ragone, and S. Fiore, Appl. Clay Sci. 53, 414 (2011).

19. L. Frankowski, J. Bolalek, and A. Szostek, Estuar. Coastal Shelf Sci. 54, 1027 (2002) .

20. F. Aydin, A. Saydut, B. Gunduz, I. Aydin, and C. Hamamci, CleanSoil Air Water 40, 444 (2012).

21. I. Aydin, F. Aydin, E. Kilinc, M.Z. Duz, and C. Hamamci, Chem. Speciation Bioavail. 25, 111 (2013).

22. N. Mlynarczyk, M. Bartoszek, J. Polak, and W.W. Sulkowski, Appl. Geochem. 37, 87 (2013).

23. A. Samadi-Maybodi, H.T. Saffar, S. Khodadoust, H.N. Saravi, and S. Najafpour, Spectrochim. Acta, Part A, 113, 67 (2013).

24. K. Ivanov, P. Zaprjanova, M. Petkova, V. Stefanova, V. Kmetov, D. Georgieva, and V. Angelova, Spectrochim. Acta, Part B, 71, 117 (2012).

25. M. Karydis, and D. Kitsiou, Environ. Monit. Assess. 184, 4931 (2012). 